\title{
The influence of public opinion on tobacco control policy-making in Georgia: Perspectives of governmental and non-governmental stakeholders
}

\author{
George Bakhturidze ${ }^{1,2,3}$ Nono Peikrishvili², Maurice Mittelmark ${ }^{3}$
}

\begin{abstract}
INTRODUCTION Georgia has one of the highest smoking rates (36\%) in Europe. This may be due partly to the fact that the present Georgian tobacco control regulations are weakly enforced. It is unclear if the authorities are aware that they would have majority public support for tighter enforcement of tobacco control regulations. The study aimed to fill a knowledge gap by addressing these research questions ${ }^{1}$ : To what degree are policy makers aware of the Georgian public's opinions about tobacco control and enforcement ${ }^{2}$ ? To what degree do policy makers take Georgian public opinion into account in their decision-making, including tobacco control and enforcement?

METHODS This study used a collective case study methodology. The data were obtained through 12 semi-structured interviews during the period from April to May 2013, with three respondents each from the Ministry of Health, the Parliament of Georgia, Opinion Research Agencies and NonGovernmental Organizations. Thematic Network Analysis was used to analyze the interview data. RESULTS Policy-makers are aware that public opinion favors tobacco control and enforcement. However, Georgian politicians do not take public opinion into account during policy-making. Tobacco industry influence is very strong in the Georgian policy-making arena. Some policy-makers are themselves lobbyists for the tobacco industry, and ignore public opinion. Public health planning and strategy development occur without public involvement.

concLusions Georgia faces a challenge in increasing the influence of public opinion in health policy making generally, and in tobacco control in particular.
\end{abstract}

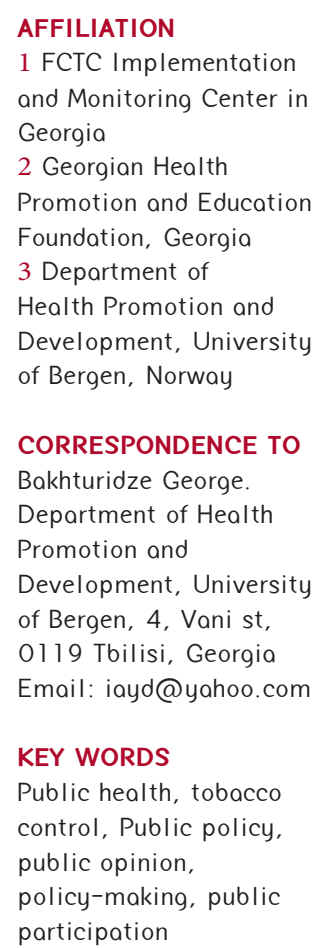

\section{INTRODUCTION}

To support the public health effort to control tobacco use, research was conducted to study public opinion regarding tobacco control ${ }^{6,7}$. This revealed majority support for tobacco control (85\% approval), even among tobacco users $(71 \%$ of female and $87 \%$ of male smokers approving strict tobacco control). Given the strong level of public support for tobacco control, from a public health standpoint the main challenge in Georgia is to stiffen the enforcement of existing controls. On the face of it, strong public opinion favoring tobacco control should create an atmosphere supporting strong enforcement. As reviewed below, research in many countries indicates that public opinion has a meaningful role to play in the degree to which tobacco control is pursued as a public health priority. With Georgian public opinion research showing strong support for enforcement, yet with enforcement being lax, two questions arise that this article addresses: Are Georgian health policy makers and authorities sensitive to public opinion about tobacco control and enforcement? If they are, what is their level of understanding of the Georgian public's support for tobacco control enforcement? Answers to these questions should help to identify the next steps to strengthen Georgian tobacco control. If the authorities tend to discount or ignore public opinion in this context, advances in tobacco control will first require a strengthening of the responsiveness of authorities to public opinion. If, on the other hand, the problem is a lack of awareness of public opinion, educational efforts are needed to inform the authorities about the actual state of public support for tobacco legislation enforcement. Combined strategies will be required to the extent that both these scenarios are evident. The challenges to tobacco control described above are, of course, not unique to Georgia. Poor enforcement of tobacco control policies and the interference of the industry is commonplace in Eastern Europe, undermining 
progress in tobacco control. Positive attitudes from the public without effective enforcement do not translate into compliance with the $\mathrm{law}^{9,10}$. For example, full protection from secondhand smoke is only achieved when compliance with smoking bans is high. Compliance is related to public support but also knowledge of second hand smoke hazards ${ }^{11}$, both influenced by media campaigns and by advocacy efforts ${ }^{11}$.

\section{Public opinion in policy-making processes}

Methods to ascertain public opinion include referenda, elections, public demonstrations and electoral research. Public opinion polls, especially, are rapid barometers by which policy makers detect public preferences ${ }^{12,13,14}$. There is evidence that public opinion can translate into policy in significant ways, at least in some arenas. For example, much of civil rights legislation in the USA was enacted only after public support was expressed repeatedly and forcefully in the American mass media.15 There is some controversy about the relative impact on policy makers of public opinion versus interest group pressure versus research on policy makers ${ }^{16}$. Still, Burstein's $(2104)^{17}$ summary of the public policy literature concludes that public opinion is a significant force for policy change, in the USA and in other Anglo - Saxon countries. This is also evident in cultures as disparate as those of Western and Eastern Europe. . $4,16,18-21^{-1}$

In the study of policy responsiveness to public opinion, perhaps the most influential theorist is Kingdon $(2011)^{22}$. His theory of political agenda setting includes consideration of the role of public opinion and he provides a framework within which to study the public's influence. Kingdon's core idea is that three distinct influence 'streams' - policies, problems, and politics - sometimes intertwine at 'policy windows', moments when external or internal forces push an issue to the top of the political agenda ${ }^{22,23}$. These forces include public opinion and other interests arising from business and industry, professional associations, civil servants, labor groups, welfare advocates, lobbyists and the mass media:

"Health officials know, for instance, that the nation's bill for medical care could be lowered considerably by a change in such health habits as smoking, drinking, and reckless driving. But they feel keenly the limits on government action in this area". Kingdon (2011, p. 65) ${ }^{22}$.

An illuminating example of the policy window concept is the experience with tobacco control in the USA. The US Surgeon General's report in 1964 clearly opened a policy window for taking major steps towards comprehensive tobacco control ${ }^{24}$, contributing to the enactment of landmark control policies and now in force in many USA States. Indeed, research worldwide reveals that the public everywhere, including tobacco users, seem to be aware of the dangers of tobacco and support tobacco control. In Australian research, 89\% of never-smokers reported supporting a workplace-smoking ban, compared with $67 \%$ smokers $^{25}$, and only a minority of Australian tobacco users reported support for smoking in public bars ${ }^{26}$. In South Africa, $83 \%$ of non-smokers and $70 \%$ of smokers supported bans on smoking in public places ${ }^{27}$. In Greece, smokers and non-smokers were equally supportive of bans on tobacco sales to minors ${ }^{28}$. In Hungary, almost $80 \%$ supported smoking restrictions in closed and outdoor public places, work places, restaurants and bars ${ }^{29}$.

Closer to Georgia, Ukrainian public support for banning smoking in educational and health premises exceeded $94 \%$ and reached $67.1 \%$ for drinking bars ${ }^{30}$. Russian studies showed that $95 \%$ of the public supported a ban on indoor smoking in healthcare premises, and $99 \%$ supported a ban in schools ${ }^{31}$.

In view of the above, the present study aimed to fill a knowledge gap by addressing these research questions:

1. To what degree are policy makers aware of the Georgian public' opinion about tobacco control and enforcement?

2. To what degree do policy makers (and those who try to influence policy makers) take Georgian public opinion into account in their decision making regarding key public health issues, including tobacco control and enforcement?

\section{METHODS}

\section{Study Design and Sompling}

This study used a collective case study methodology ${ }^{32}$.

\section{Methods and interview process}

The data were obtained through 12 semi-structured interviews during the period from April to May 2013, with three respondents each from the Georgian Ministry of Labor, Health and Social Affairs (MOH case), the Parliament of Georgia (MOP case), Opinion Research Agencies (ORA case) and Non-Governmental Organizations (NGO case). Respondents were selected based on their having extensive public health portfolios within their respective organizations. Face-to-face, one-on-one interviews were conducted in Georgian by the first author. They were audio recorded.

\section{Thematic Network Analysis and Coding}

The second author prior to further data analysis listened to all the recordings. The second author then transcribed the tapes in Georgian. All tapes were transcribed before analysis began. Thematic network analysis (TNA) was used to analyze the interview data ${ }^{33}$. The TNA was undertaken by the second author using the Georgian transcripts. The intent to have 
the second author undertake the analysis was to distance the analysis from the first author and his interview context/ experience. TNA is a hermeneutic approach to extracting the lowest-order of meaning, referred to as Basic Themes. This was done in Georgian. The Basic Themes were grouped and summarized into Organizing Themes, also done in Georgian. These were further abstracted in Georgian into super-ordinate Global Themes.

In coding the transcripts, basic, organizing and global themes were identified without regard to the sources of the data, with the second author having no access to the identities of the interviewees (beyond what might be guessed/surmised by the content of an interview). The first and second authors then constructed a graphical network depiction of the theme structure. Only after this stage in analysis were the themes cross-identified with the cases, to ascertain which cases contributed information to which themes.

The first and second authors then returned to the transcripts to search for case-specific data to illustrate the evidence for the themes. Selected quoted material was then translated to English (the transcripts themselves were not translated into English). All authors then discussed the Georgian-English translations and agreed that close/literal translations resulted in close to unintelligible English. This stemmed in good part from the interviewees' frequent use of jargon and phraseology commonly used in the Georgian policymaking and public administrative arena, but having obscure meaning in everyday Georgian.

The decision was then taken to paraphrase the Georgian quotes in English, to avoid giving the impression of precise translation. Therefore, material obtained from the interviewees as reported in this paper appears without quotation marks, and in paraphrased form only. The Georgian transcripts are available from the first author, which permits an independent analysis.

\section{Ethics stotement}

The Georgian Health Promotion and Education Foundation Ethical Committee approved the study protocol, which complied with the current laws of the country. Signed informed consent was obtained from all participants. Neither the raw data nor the data analysis files contain information that can identify the respondents.

\section{RESULTS}

BBefore presenting the results, we can underline that all respondents were collaborative and none refused to participate in our study.
The global theme driving the TNA is the public's role in public health policy making as perceived by the respondents. The TNA revealed three organizing themes: A) The public has an opinion; B) Public opinion is ignored or manipulated; C) Public opinion not influential in tobacco control and 13 basic themes as shown in Figure 1. The basic and organizing themes on the role of public opinion in public health policy making are presented in Table 1. As shown, a "+" sign is assigned to similar responses of all respondents from the appropriate stakeholder group (case representatives). In most cases there are similar positions from the different stakeholder groups.

Organizing Theme A is labeled 'The public does, indeed, have opinions'. That, at least, is how the respondents perceived it. They had no trouble describing their perceptions of public stances on a variety of health issues that were probed by the interviewer. The four basic themes supporting this interpretation cover a range of health topics.

Basic Theme 1 arises from respondents' claims that public opinion related to illicit drugs has always been strongly negative. Only a small minority of the public is seen to support marijuana decriminalization, and according to MOP respondents, this minority can and should be ignored.

Basic Theme 2 follows from respondents' comments about sex education and family planning. In general family planning and sex education is stigmatized in Georgian society. NGO, $\mathrm{MOH}$ and ORA respondents indicated that strong public opinion against contraception and sex education hindered policymakers' intentions to address these sensitive issues. As an ORA respondent put it, 'the main hindering force [for family planning policy] was public opinion'.

Basic Theme 3 is stimulated by the changing public stance on an issue relevant to almost everyone; the requirement to use seat belts in moving vehicles. Respondents remembered that public opinion on the compulsory use of seat belts was not supportive before legislation was enacted in 2010. Yet, as the majority of respondents remarked, public support increased after enforcement became a reality.

Basic Theme 4 arose out of expressions connected to drinking water quality. Despite the fact that Georgia is rich in water resources, there are still problems with water supply and water quality. Several respondents remarked that the public attitude is united in calling for safe water, sewerage systems, proper waste management, and permanent supplies of quality drinking water. Taken together, these basic themes suggest that Georgian policy makers have some awareness of public opinion on a range of health issues. That conclusion ties in with Organizing Theme B: is public opinion perceived to matter in policy-making processes, or is it ignored, or is it manipulated? 
The Basic Themes informing Organizing Theme B suggest that the respondents perceive that public opinion is ignored rather than regarded in policy processes.

Basic Theme 5 arises from respondents' reports that during Shevardnadze's leadership (1992-2003), public opinion was not monitored via polls or other means polls, even if the public was presumably informed by the relatively free mass media. During Saakashvili's leadership (2004-2012), public participation in policy-making processes did not increase, and nor has it since. Most of the respondents simply did not believe that policy-making in Georgia is affected by public opinion. Rather, the perception is that private vested interests always have been a dominant influence. Yet, the $\mathrm{MOH}$ respondents believed that the fundamental expression of democracy is when public opinion and public policy interact. Thus, at least at a private level among some policy-makers, there may be a desire for a greater role in policy-making than seems to have been the case. For example, NGO and ORA respondents argued that government should increase the involvement of the public in order to enhance the public's connections with governmental officials. They believed that in general, decisions are made without considering public opinion and policymaking processes are dominated by the elite's interests. All respondents mentioned in one way or another that there is no political will to involve the public in policy-making.

Basic Theme 6 is very closely related to Basic Theme 5; the latter deals with the perception that public opinion is ignored, while the former deals with the conviction that public opinion should count. Most of the respondents believed that government should be more willing to consider public opinion in policy formation. NGO respondents underlined the potential for better policy-making if the public were to be involved. ORA representatives underlined potential importance of public opinion polls in policy-making. MOP and $\mathrm{MOH}$ group respondents assumed that national mood is important in decision-making when it supports the decisions

Table 1. Basic and organizing themes on the role of public opinion in public health policy making

Public opinion has very little consideration in policy making generally

Policy makers have little interest in involving public in decision-making

Public opinion has very little consideration

Public is considered 'dangerously' uninformed

Public opinion polls have been used for manipulation

Media have been used for manipulation

Public opinion data are not regularly collected

Public opinion has little influence on public health policy-making in particular

Public opinion to combat illicit drugs is very supportive

Public opinion was negative on sex education and family planning from early stages

Public opinion support increased sufficiently after the seat belt regulations entered into force

Public has little interest in quality of drinking water

Donors have some positive influence on policy-making

Public opinion is not considered in tobacco control policy-making

It is important to consider public opinion regarding tobacco control

It is not important to react to public opinion regarding tobacco control

Media role is weak on tobacco control

No tobacco control policy enforcement

Tobacco industry influence is strong

Donors have positive interest in supporting tobacco control

\begin{tabular}{|c|c|c|c|}
\hline МOP* & МОЛ I** & $\mathrm{NGO}^{* * * *}$ & OR $\Lambda^{* * * *}$ \\
\hline \multirow{4}{*}{+} & + & + & + \\
\hline & + & + & + \\
\hline & + & & \\
\hline & & + & + \\
\hline \multirow{6}{*}{+} & & + & + \\
\hline & + & + & + \\
\hline & + & + & + \\
\hline & + & & \\
\hline & + & + & + \\
\hline & + & + & + \\
\hline+ & & + & + \\
\hline+ & & + & \\
\hline \multirow{4}{*}{+} & + & + & + \\
\hline & & & \\
\hline & & + & + \\
\hline & + & + & \\
\hline \multirow{3}{*}{+} & + & + & \\
\hline & + & + & \\
\hline & + & + & \\
\hline
\end{tabular}

Public opinion is very supportive for strong tobacco control measures and requests enforcement

+ Means similar responses of all respondents from appropriate stakeholder group (case)

* MOP - Members of Georgian Parliament

** MOH - High officials of the Georgian Ministry of Labor, Health and Social Affairs

*** NGO - Heads of relevant Non-Governmental Organizations

**** ORA - Heads of Opinion Research Agencies 
preferred by the elite. Basic Theme 7 suggests that one reason public opinion may be ignored is that it is considered to be dangerously ill-informed. MOP and $\mathrm{MOH}$ respondents declared that sometimes public opinion on a particular issue is ill-informed and is against the course of action that is best (as seen by 'experts'). Hence, they ignore such opinions, citing the need to avoid potential danger. This thought was expressed in a general way, and not with reference to particular policy issues.

Basic Theme 8 illuminates the opinion of some respondents that beyond simply ignoring public opinion, the public mood is sometimes studied and then used for manipulation. ORA representatives mentioned that in earlier times, instruments were used to listen to the 'heart beat' of the public. These instruments were research surveys repeated 3-4 and more times a year (during the period 2004-2012). Also used were league tables and other data sources. The data were accumulated in one database, which was used to manipulate the public and steer policy processes including health care policy making. PO respondents believed that during the era of Saakashvili, knowledge about public opinion was used to enhance success during election periods, but was otherwise used to manipulate the public in the direction of policy preferences of the dominant political regime.

Basic Theme 9 is closely related to Basic Theme 8: its focus is the perception that the mass media has been an important mechanism in public opinion manipulation. The mass media are seen as always serving the interests of the elite. Sometimes the mass media is seen to distort critical facts, or omit vital stories or details, in order to manipulate the public. One NGO respondent remarked that today, the mass media are selective, if any pro-tobacco control public event is planned, media coverage is neutral. An ORA respondent claimed that since 2004 the mass media are fully controlled, which has resulted in the total non-support of tobacco control by the media.

Basic Theme 10 is based on respondents' recollection that during the Saakashvili era, public opinion data were collected periodically in order to manipulate policy outcomes, even if not to actually inform decision-making processes. At the time of the interviews, NGO, $\mathrm{MOH}$ and ORA respondents felt there was no real interest to conduct public opinion research, for any purpose whatsoever.

Turning to Organizing Theme C, tobacco control comes into focus. The basic themes illuminate a dissonance between two perceptions: the public is known to support tobacco control and this should count, but the public's opinion about tobacco control is ignored.
Basic Theme 11 is adressed by $\mathrm{MOH}$ and $\mathrm{NGO}$ respondents who underlined the importance of public opinion when consideringtobaccopolicy.ORA,NGO and MOHrepresentatives remarked that public opinion regarding tobacco control is supportive, but the Government does not take it into account in its policy-making. This is due in part, some respondents remarked, to the tobacco industry providing opposite and misleading information to the Government, suggesting that there is a negative public mood towards strong measures like a total ban of smoking in public places, a tobacco tax increase, ad bans, and so forth. NGO and $\mathrm{MOH}$ respondents addressed the powerful influence of commercial interests against tobacco control and the embroilment of the Government, with one remarking that Georgians live in a country where politicians are richer than businessmen, and Government officials are the lobbyists for the tobacco industry.

Basic Theme 12 is not focused on the public itself, but on Donors' support for tobacco control, which is seen by respondents to be in synchrony with Georgian public opinion. The strong support of the international public health community for tobacco control was remarked on by NGO, MOP and MOH respondents, with one saying that international organizations and donors have ideological and financial influence in the policy formation process, a positive example of which is the World Health Organization's Framework Convention on Tobacco Control. Donors, NGO respondents said, make ideological contributions, investments and help with policy design. MOP respondents noted that donors are one of main players in policy making and their influence is important. Furthermore, international obligations were found to be important, such as the motivation to implement EU regulatory regimes.

Basic Theme 13 raises for the first time the influence of Georgian tobacco users. MOP representatives expressed a widely held view that smokers' reaction will be strongly negative to tobacco control measures, and thus outweigh public opinion favoring tobacco control. This creates inertia for tobacco control, exacerbated by pressure from the tobacco industry. The industry, respondents say, tries to oppose tobacco control efforts in all possible ways. Policy-makers are aware that public opinion favors tobacco control and enforcement, but politicians are resistant; they support business including the tobacco industry, and ignore public opinion. $\mathrm{NGO}$ and $\mathrm{MOH}$ respondents mentioned that even the weak tobacco control policies in place during Saakashvili period were not enforced. The NGO respondents remarked that public health interest was ignored, and planning and strategy development occurred without public involvement. 


\section{DISCUSSION}

It is important to recall the reason this study was undertaken, to establish a framework for a discussion of the above findings. Two recently published studies from Georgia revealed strong majority support for tobacco control (more than 80\%), including support from tobacco users ${ }^{6,7}$. The academic literature suggests that public opinion may play an important role in public policy making, in communities where public opinion carries weight in political processes. The majority of Georgians support enhanced tobacco control according to the new research, but can this have weight in Georgian political decision-making processes in the tobacco control arena? We cast the issue in the form of two research questions: (1) To what degree are policy makers aware of the Georgian public' opinion about tobacco control and enforcement? (2) To what degree do policy makers (and those who try to influence policy makers) take Georgian public opinion into account in their decision making regarding key public health issues, including tobacco control and enforcement?

The short answers are these: (1) our respondents were of the opinion that many Georgians favor tobacco control (and recent research indicates this is correct), but (2) the public's opinion carries little weight, especially in comparison to the influence of the tobacco industry. This is a sobering finding. Yet it seems likely that Georgian policymakers are not aware of the overwhelming support of the public for strong tobacco control, nor that most smokers also favor tobacco control ${ }^{6,7}$. The recent and compelling evidence on this may heighten policy-makers awareness of the actual state of public opinion, and that might increase motivation to adjust tobacco policy in directions favored by the majority of the public. There may be grounds for optimism, but it will be essential that public health advocates find ways to illuminate the recent findings about public opinion so that policy-makers are confronted emphatically with the facts of the matter.

The barriers are formidable. Grass-roots involvement and participation, which is the Ottawa Charter's basis ${ }^{3,4}$ is not sufficiently practiced in health policy-making processes in Georgia. The health policy-making rhetoric in Georgia has evolved from a soviet focus based on a top-down expert model. For example, in 2006 the Prime Minster called for the involvement of all key stakeholders in policy-making ${ }^{35}$. However, the instruction 'to involve' stakeholders could be interpreted in many ways. Using the Bishop and Davis' model, the current situation in Georgia is that participation is merely on the 'consultation' level ${ }^{20}$. The paper by Hauschild and Berkhout ${ }^{36}$ is the only empirical study of this issue from Georgia, and it concludes that very little is actually known about how the government plans to involve stakeholders, how they actually attempt to involve them, and how the government and the stakeholders perceive their involvement:

"Many stakeholders (the general public, health professionals, health insurance companies, donors and non-government organizations (NGOs)) stated that they have not been properly consulted about proposed reforms; decision-making processes lack transparency..."

In theory, the Ministry of Health is not the only responsible body addressing major health challenges; it is the task of the entire government, which should enact healthy public policies in all sectors and health monitoring ${ }^{37,34}$. Citizens generally lack the awareness of the principles of health promotion and to some extent do not believe that they can contribute to their own health ${ }^{38}$. Thus, the conditions for health promotion in Georgia today are bleak, characterised by a lack of political will to prioritize health, lack of public involvement in policymaking processes, the complexity of multi-sectorial work in a politically difficult environment and inadequate human and financial resources for health promotion ${ }^{37-39}$.

It should be noted that the respondents from governmenta 1 organizations and the members of Parliament were mostly connected to the ruling political party. Yet they did express considerable critical comments regarding the role of public opinion in policy-making engendering confidence in the validity of the interview data. Of more concern is the issue of translation from Georgian to English. We attempted close translation using the translation-re translation method, but the tone of the respondents' comments could not be communicated well in English in the limited space of a scientific paper. We therefore elected to take a conservative approach, using paraphrasing as explained in the Methods. However, the complete Georgian transcripts of the interviews are available for independent analysis.

\section{CONCLUSIONS}

Greater transparency is needed in tobacco control policymaking in Georgia, to illuminate and prevent tobacco industry interference, and increase responsiveness to public opinion. WHO DG announced in 2013 the End Game policy, which aims to decrease tobacco consumption dramatically, to a maximum of five percent tobacco use prevalence globally by 2050; European countries aim to achieve this goal by $2040^{40,}$ ${ }^{41}$.In Georgia, political will must strengthen significantly if the country is to implement international obligations connected to the FCTC and the Tobacco End Game strategy. On a positive 
note, there is some evidence that policy-makers are now more aware of public support for tobacco control. The new Georgian State Strategy was set in Resolution N196 ${ }^{42}, 30.07 .13$, and the Resolution highlights recent evidence on the public's support for tobacco control ${ }^{6,7}$. The Resolution acknowledges that "public support is important to provide tobacco control measures effectively". Yet there is reason for skepticism. It is one side of the issue to mention such research results in a policy document, but quite another side is the continued very low level of enforcement of current tobacco control regulations. The public strongly supports tobacco control; will the democratic imperative to listen to the voice of the people propel Georgia to an ever more stringent tobacco control policy, and rigorous enforcement? Georgian democracy is new. There remain challenges to increasing public participation and consideration of public opinion in policy-making processes generally. This is also true in the tobacco control policy arena, where the most important player is still the tobacco industry and not the public interest.

\section{REFERENCES}

1. Bakhturidze GB, Ross H, What J, et al. Population survey on tobacco economy and policy in Georgia. FCTC Implementation and Monitoring Center in Georgia 2008; 4-22.

2. Gilmore A, Pomerleau J, McKee M, et al. Prevalence of Smoking in 8 Countries of the Former Soviet Union: Results From the Living Conditions, Lifestyles and Health Study. American Journal of Public Health 2004; 94(12): 2177-87. doi: 10.2105/AJPH.94.12.2177

3. Georgian Law on Tobacco Control. Available at: https://matsne.gov. ge/en/document/view/1160150 (accessed 12 Dec 2010)

4. Administrative Offences Code of Georgia. Available at: https:// matsne.gov.ge/en/document/view/28216 (accessed 11 Dec 2015)

5. WHO. Parties to the WHO Framework Convention on Tobacco Control. Available at: http://www.who.int/fctc/signatories_parties/ en/index.html (accessed 12 Feb 2015)

6. Bakhturidze G, Peikrishvili N, Mittelmark M, Aaro L. The public's attitudes towards tobacco sales prohibitions: Evidence from a nationally representative survey in the former Soviet state of Georgia. Tobacco Control and Public Health in Eastern Europe 2012; 2(2):99-108. doi: 10.6084/m9.figshare. 97675

7. Bakhturidze G, Mittelmark M, Aaro L, Peikrishvili N. Attitudes towards smoking restrictions and tobacco advertisement bans in Georgia. BMJ Open 2013; 3:1-10. doi: 10.1136/bmjopen-2013-003461.

8. Framework Convention on Tobacco Control (FCTC), Secretariat mission Report for Georgia, 2013. Available at: http://ncdc.ge/pdf/ ENG631.pdf

9. Ravara S, Castelo-Branco M, Aguiar P, Calheiros J. Compliance and enforcement of a partial smoking ban in Lisbon taxi: an exploratory cross-sectional study. BMC Public Health 2013, 13:134. doi: 10.1186/1471-2458-13-134

10. Vardavas C, Dimitrakaki Ch, Schoretsaniti S, et al. The role of the non-smoker in enforcing smoke-free laws. Journal of Public Health Policy 2011, 32, 46-59. doi:10.1057/jphp.2010.45
11. Nagelhout G, De Vries H, Fong G, et al. Pathways of Change Explaining the Effect of Smoke-Free Legislation on Smoking Cessation in the Netherlands. An Application of the International Tobacco Control Conceptual Model. Nicotine Tob Res (2012) 14 (12): 1474-1482.

doi: $10.1093 / \mathrm{ntr} / \mathrm{nts} 081$

12. Soroka SN, Wlezien C. Opinion representation and policy feedback: Canada in comparative perspective. Can Political SciAssoc 2004, 37:531-59.

13. Petry F. How policy makers view public opinion. University of Toronto Press 2005, 6:1-32.

14. Brooks J E, Manza J. Social policy responsiveness in developed democracies. Am Sociol Assoc 2006, 71:474-94.

15. Monroe, A. Public Opinion and Public Policy, 1980-1993. The Public Opinion Quarterly 1998, 62(1):6-28.

16. Warner K, Tam J. The impact of tobacco control research on policy: 20 years of progress. Tobacco control 2012, 21:103-109. doi:10.1136/tobaccocontrol-2011-050396

17. Burstein P. American Public Opinion, Advocacy, and Policy in Congress: What the Public Wants and What It Gets. Cambridge University Press 2014:1-19, 45-70.

18. Johnson M, Brace P, Arceneaux K. Public opinion and dynamic representation in the American States: the case of environmental attitudes. SocSci 2005, 86:88-105. doi: 10.1111/j.0038-4941.2005.00292.x

19. Weakliem DL. Public opinion research and political sociology. Research in Political Sociology 2003, 12:49-80.

20. Bishop P, Davis G. Mapping Public Participation in Policy Choices. Australian Journal of Public Administration 2002, 61(1):14-29. doi: $10.1111 / 1467-8500.00255$

21. Horne C. The Consistency of Policy with Opinion in the Russian Federation, 1992-2006. Journal of Elections, Public Opinion and Parties 2012, 22(3):215-244. doi: $10.1080 / 17457289.2012 .691882$

22. Kingdon J. (2011) Agendas, Alternatives, and Public Policies. Longman classics in political science 196-208.

23. Howlett M, Ramesh M. Studying public policy - policy cycles and policy subsystems. Oxford University Press 2003, 129, 163, 185204.

24. Fritschler L, Rudder. Smoking and politics. Bureaucracy centered policymaking. Pearson Education, Inc 2007, 12-43, 155-173.

25. McAllister I. Public opinion in Australia on restricting smoking in public places. Tob Control 1995, 4:30-5. doi:10.1136/tc.4.1.30

26. Trotter L, Mullins R. Environmental tobacco smoke: surveys of restaurant patrons and hospitality industry personnel. Quit Eval Stud 1996, 9:27-41. doi:10.1136/bmjopen-2013-003461

27. Reddy P, Meyer-Weitz A, Yach D. Smoking status, knowledge of health effects and attitudes towards tobacco control in South Africa. S Afr Med J 1996, 86:1389-93.

28. Lazuras L, Rodafinos A, Panagiotakos DB et al. Support for smokefree policies in a pro-smoking culture: findings from the European survey on tobacco control attitudes and knowledge. Int J Public Health 2009, 54:403-8. doi: $10.1007 / \mathrm{s} 00038-009-0074-2$

29. Paulik E, Maroti-Nagy A, Nagymajteni L et al. Support for population level tobacco control policies in Hungary. Cent Eur J Public Health 2012, 20:75-80.

30. Andreeva T, Kharchenko N, Krasovsky K et al. Global Adult Tobacco Survey (GATS), Ukraine. WHO, Country Report 2010. 
Research Article

Available at: http://www.who.int/tobacco/surveillance/en_tfi_gats_ ukraine_report_2010.pdf

31. Chuchalin A, Sakharova G, Antonov N et al. Global Adult Tobacco Survey (GATS), Russian Federation. WHO, Country Report 2009. Available at: http://www.who.int/tobacco/surveillance/en_tfi_ gats_russian_countryreport.pdf

32. Creswell J. Qualitative Inquiry and Research Design. Choosing among five Approaches. 2nd ed. Thousand Oaks, CA 2007, Sage: 35-41.

33. Attride-Stirling J.A (2001) Thematic networks: an analytic tool for qualitative research. Sage. Qualitative Research 1(3):385-405. doi: $10.1177 / 146879410100100307$

34. WHO. The Ottawa Charter for Health Promotion. 1986. Available at: http://www.who.int/healthpromotion/conferences/previous/ ottawa/en/

35. Chanturidze T, Ugulava T, Duran A et al (2009) Georgia; Health system review. Health Systems in Transitions 11(8):85.

36. Hauschild, T and Berkhout, E. Health-care reform in Georgia; A Civil-Society Perspective: Country Case Study. Oxfam International $2009,36$.

37. UNICEF and National Center for Diseases Control of Georgia (NCDC). Evaluation of Health Promotion and Communication system Georgia 2010, 1-60. Available at:

http://ncdc.ge/uploads/publications/Evaluation_of_Health_ Promotion_and_Communication_system_2010.pdf

38. Chanturidze T. Lessons learned: developing the health promotion strategy and action plan in Georgia. Oxford Policy Management 2010, 5:1-4

39. Raminashvili D, Bakhturidze G, Zarnadze I et al. Promoting health in Georgia. Global Health Promotion 2014, 21(1):5-12.

40. WHO. The International Conference on Public Health Priorities in the 21st Century: The Endgame for Tobacco (2013) Available at: http://www.endgameconference2013.in/

41. WHO-Euro. European Tobacco Control Status Report 2013. Available at: http://www.euro.who.int/_data/assets/pdf_file/0011/235973/ European-Tobacco-Control-Status-Report-2013-Eng.pdf?ua=1

42. Government of Georgia on Approval of Georgian State Strategy on Tobacco Control. Resolution N 196, 30.07.2013. Available at: https://matsne.gov.ge/index.php?option=com_ldmssearch\&view= docView\&id=1978972\&lang=ge

DECLARATION OF COMPETING INTERESTS

The authors have completed and submitted the ICMJE Form for Disclosure of Potential Conflicts of Interest and none were reported.

\section{FUNDING}

The Eurasia Program administered by the Norwegian Center for International Cooperation in Higher Education and the Norwegian Ministry of Foreign Affairs, provided financial support for first author in the study's data analysis and report writing phase.

PROVENANCE AND PEER REVIEW

Not commissioned;

externally peer reviewed 